\title{
Practical Field Test on Newly Designed Burial Type Lowland Power Cultivator for Effective Weed Control in North-Central Province of Sri Lanka
}

\author{
G.V.T.V. Weerasooriya ${ }^{*}$, D.N. Jayatissa ${ }^{1}$ and M. Rambanda ${ }^{2}$ \\ Postgraduate Institute of Agriculture \\ University of Peradeniya \\ Sri Lanka
}

\begin{abstract}
Weed competition causes significant reduction of rice yield in Sri Lanka. Power weeders have been promoted as an alternative measure to face restricted use of some of the weedicides in Sri Lanka. A new burial type lowland power cultivator has been designed; however, has not been field tested yet hence not been considered for recommending to farmers. Therefore, this study was conducted to test the suitability/adaptability of this new cultivator under the field conditions. When tested the cultivator showed satisfactory field performances with 0.03 ha/h effective field capacity, $83.25 \%$ field efficiency, $80 \%$ weeding efficiency, and 580 performance Index. Despite $6.34 \%$ plant damages, 22 maximum number of tillers, $6968 \mathrm{~kg} / \mathrm{ha}$ paddy yield was recorded. Further the calculated cost for weeding was Rs. 7671/ha under the field test. Further, the calculated fuel consumption, labour and power requirement were $0.503 \mathrm{~L} / \mathrm{h}, 33 \mathrm{man}$ - $\mathrm{h} / \mathrm{ha}$ and $0.319 \mathrm{~kW}$, respectively. Interestingly, no ergonomic or mechanical defects were reported during the field test. Given above, new burial type lowland power cultivator can be considered for recommending to farmer after conducting further detail ergonomic evaluations via future investigations.
\end{abstract}

Keyword: burial type cultivator, chemical weeding, power weeder, practical field test

\section{INTRODUCTION}

Weed is one of most important agricultural pests. Most of the weeds compete more efficiently for their nourishment than the crop. This competitive nature of weeds causes serious negative effect in crop production. Similarly, weeding is a laborious operation and it accounts for about $25 \%$ of total labour requirement during the cultivation season (Yadav and Pund, 2007). This probable yield loss due to unrestricted weed competition and the huge labor force required is unbearable and affects badly to the rice production in Sri Lanka. Proper weeding technology is also an important factor to the Sri Lankan farmers for reducing labour requirements and production costs.

The chemical methods of weed control had gained popularity among medium and large scale farmers in Sri Lanka, over other available methods which are laborious, arduous, time consuming, leading to higher cost of production and particularly limited to small scale farming. However, over usage of agro-chemicals, causes negative impact on the environment

\footnotetext{
${ }^{1}$ Department of Agricultural Engineering, Faculty of Agriculture, University of Peradeniya, Sri Lanka

${ }^{2}$ Department of Agricultural Engineering, University of Peradeniya

*Corresponding Author: gvtvw@agri.rjt.ac.lk
} 
and human health. Similarly, some herbicides are banned in Sri Lanka recently to minimize the potential health impact. However, there should be an appropriate alternative approach to control weeds in rice farming with minimum environmental effect.

Because of these reasons, mechanical method of weed control is imperative. It is very effective, eliminate drudgery and also keep the soil surface loose ensuring better soil aeration and water intake capacity which leads to increase the potential yield. Therefore Department of Agriculture (DOA) Sri Lanka, is promoting the usage of mechanical power weeders for medium and large scale paddy farmers as an alternative approach to chemical weed control. Similarly, it has been considered as the solution to weed control in mechanically transplanted paddy fields by advent of a mechanical power transplanter. As a result of that, several power weeders have been imported and distributed among paddy farmers. Most of them are with rotary action and not much popular among Sri Lankan farmers.

To overcome this situation, new burial type lowland power cultivator has been designed and fabricated (Plate 1). Distinguished feature of this design is the weed burying units. However this cultivator was not subjected to practical field test. Hence it is unable to confirm the machine adaptability to practical farming conditions and make recommendations. Therefore, this study was aimed test the adaptability of newly designed cultivator to real farming conditions through a practical field test.

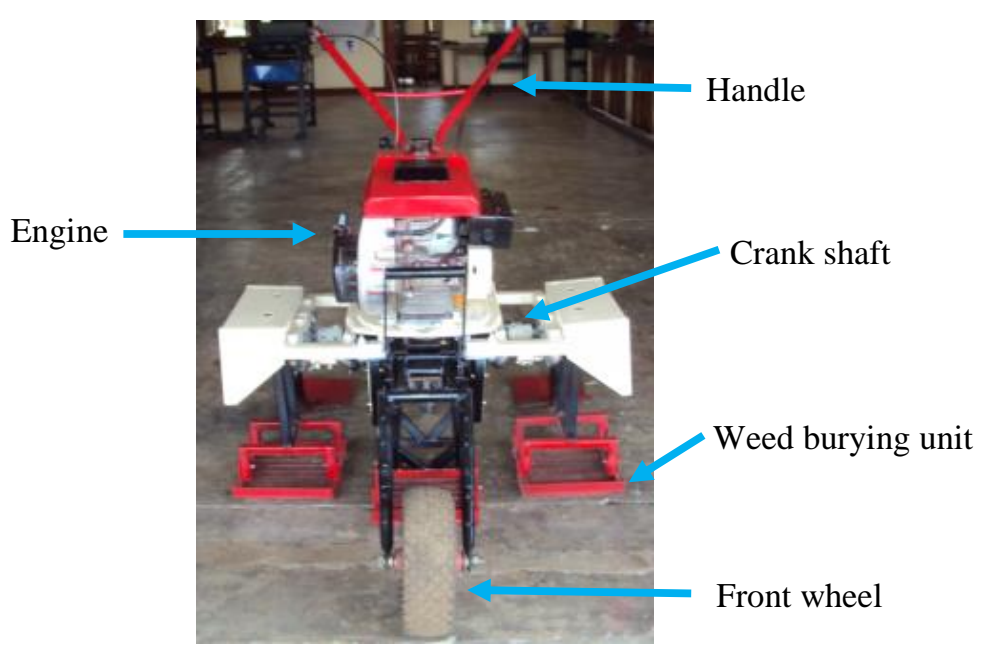

Plate 1. Newly designed burial type lowland power cultivator

\section{MATERIALS AND METHODS}

\section{Experimental Field}

These practical field tests were conducted during the 2015/16 "Maha" season on purposely selected farmer paddy fields in North Central Province (NCP) of Sri Lanka.

Mechanically transplanted (row spacing of $30 \mathrm{~cm}$ ) well grown regular shape paddy fields (at least $10 \times 20 \mathrm{~m}$ ) with $\mathrm{Bg} 352$ were selected. RNAM (1983) test codes and procedures for weeders were followed for this testing and evaluation. Five field samples from each test field 
were drawn by $50 \times 50 \mathrm{~cm}^{2}$ quadrant. Weeding operation was done at 3 weeks after transplanting (WAT).

\section{Test Conditions}

Performances of weeders vary with the conditions of the field, soil, weed, crop, power source, operator and the ambient conditions. Under the field and soil conditions; location, area of the field, soil moisture content (MC), depth of standing water, bulk density (BD) and cone index (CI) were considered. Soil MC was determined by gravimetric method (Majumdar and Singh, 2002). The core sampler $(\varnothing=50 \mathrm{~mm})$ was used to determine the BD of the soil (Singh, 1980). Eijkelkamp hand penetrometer was used to measure CI. As the weed condition; type of weed, population density, and the average height of weed were considered. Plant population and height of the plants were measured as crop conditions. In addition, the skill of the operator and condition of weather also was noted.

\section{Performance Indicators}

Machine performance (effective field capacity, field efficiency, weeding efficiency, plant damage percentage and performance index), crop growth and yield parameters (maximum tiller number and paddy yield) and cost economics (total weeding cost) were considered as field performance indicators. Besides, depth of cut, travelling speed, fuel consumptions power and labour requirement were also examined.

Field capacity, field efficiency, weeding efficiency and plant damage percentage were determined as per the standard procedure (RNAM, 1983) using equations $01-04$.

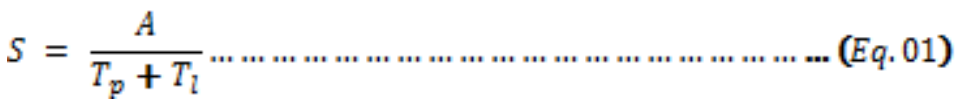

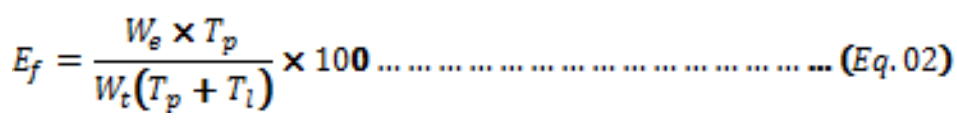

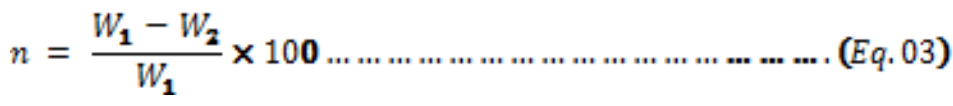

$$
\begin{aligned}
& \mathrm{S}=\text { Effective field capacity }(\mathrm{ha} / \mathrm{h}) \quad \mathrm{A}=\text { Area covered (ha) } \\
& \mathrm{T}_{p}=\text { Productive time }(\mathrm{h}) \quad \mathrm{T}_{l}=\text { Non productive time }(\mathrm{h}) \\
& \mathrm{E}_{\mathrm{f}}=\text { Field efficiency }(\%) \quad \mathrm{W}_{\mathrm{e}}=\text { Effective working width } \\
& \mathrm{W}_{\mathrm{t}}=\text { Theoretical working width } \quad \mathrm{n}=\text { Weeding efficiency }(\%) \\
& \mathrm{W}_{1}=\text { Weed count per unit area before operation } \\
& \mathrm{W}_{2}=\text { Weed count per unit area after operation }
\end{aligned}
$$$$
\text { Percentage of Plants Damaged }=\frac{Q}{P} \times 100 \ldots \ldots \ldots \ldots \ldots \ldots \text { (Eq. 04) }
$$

$\mathrm{P}$ and $\mathrm{Q}$ are the number of plants in $10 \mathrm{~m}$ row length before and after tilling operation respectively. The performance index was calculated using equation 05 as described by Srinivas et al. in 2010. 


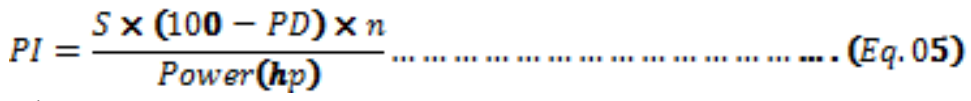

$$
\begin{aligned}
& \mathrm{PI}=\text { Performance Index } \quad \mathrm{S}=\text { Field capacity }(\mathrm{ha} / \mathrm{h}) \\
& \mathrm{PD}=\text { Plant damage }(\%) \quad \mathrm{n}=\text { Weeding efficiency }(\%)
\end{aligned}
$$

Maximum tiller number was counted at 5 weeks after transplanting (WAT) and the net plot yield (at 14\% Moisture content) was determined at the end of the season.

In order to assess the weeding cost, fixed and variable costs were calculated. The fixed cost includes depreciation cost, interest, insurance, tax, housing, repair and maintenance cost and it is a function of purchase value, useful life and interest rate. Insurance and taxes has been assumed to be negligible for this equipment. Mean annual depreciation cost and interest were determined from straight-line method (Kepner et al., 1982) by the equation 06 and 07, respectively.

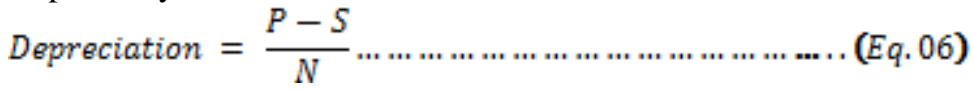

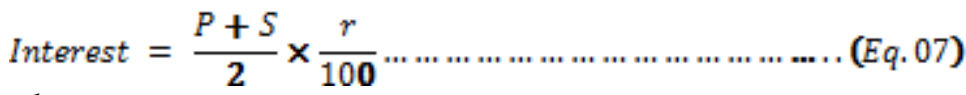

$$
\begin{aligned}
& \text { where, } \\
& \begin{array}{ll}
\mathrm{P}=\text { Purchase price } & \mathrm{S}=\text { Salvage price }(10 \% \text { of purchase price) } \\
\mathrm{N}=\text { Total life in years } & \mathrm{r}=\text { Present interest rate per annum }
\end{array}
\end{aligned}
$$

The cost for housing, repair and maintenance were $10 \%, 1.5 \%$ and $8 \%$, respectively of purchase value. Assuming annual operation of the equipment as $300 \mathrm{hr}$ hourly fixed cost was calculated.

Variable costs include fuel and lubricant and operator cost and are directly related to the amount of work done by the machine. Fuel charge has been determined based on actual fuel consumption and its prevailing rate in the market (Rs. 117/= per one liter of petrol). Labour charge has been considered as per the prevailing rate (Rs. 1000/=) per day ( $8 \mathrm{~h}$ work). Lubrication charge has been assumed as $10 \%$ of the fuel charge.

The equation 08 was used to determine the cost of operation as suggested by Hunt (1995)

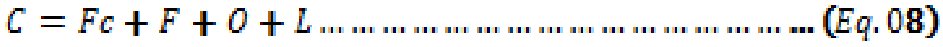

where;

$$
\begin{array}{ll}
\mathrm{C}=\text { Cost of operation }(\text { Rs. } / \mathrm{h}) & \mathrm{Fc}=\text { Hourly fixed cost }(\text { Rs. }) \\
\mathrm{F}=\text { Fuel cost }(\text { Rs. } / \mathrm{h}) & \mathrm{O}=\text { Lubrication cost }(\text { Rs. } / \mathrm{h}) \\
\mathrm{L}=\text { Labour cost }(\text { Rs. } / \mathrm{h}) &
\end{array}
$$

The hourly total cost was converted to the weeding cost per unit area (ha) by dividing by the field capacity as discussed in RNAM, 1983.

\section{Data Analysis}

Collected data were represented using descriptive statistics. The significance of the treatments was tested using analysis of variance (ANOVA) procedure of SAS software at $0.05(\alpha)$ level. Duncan's multiple range test (DMRT) was used to separate the means of 
significant variables. Effects of test conditions were identified by fitting linear regression models.

\section{Test Field Conditions}

\section{RESULTS AND DISCUSSION}

Results of the ANOVA and mean comparison for the test field conditions are summed up in table 01 . While most of the test conditions significantly varied with farmer fields, height of the weed and plant population did not significantly vary $(p>0.05)$ among fields. It may be due to mechanical transplanted fields which facilitate fixed inter-row spacing. All the field tests were conducted using skilled operators, while avoiding extreme weather conditions to maintain the test uniformity.

Table 01. ANOVA and mean separation for the test conditions

\begin{tabular}{|c|c|c|c|c|c|c|c|c|}
\hline \multirow{2}{*}{ Source } & \multicolumn{8}{|c|}{ Test conditions } \\
\hline & MC & SW & BD & CI & WD & HW & PP & HP \\
\hline Model & $0.0016^{*}$ & $0.0004 *$ & $0.0106^{*}$ & $0.0309 *$ & $0.0094 *$ & 0.3757 & 0.0971 & $0.0232 *$ \\
\hline Field & $0.0006^{*}$ & $<0.0001 *$ & $0.0030 *$ & $0.0064 *$ & $0.0021 *$ & 0.1420 & 0.5375 & $0.0082 *$ \\
\hline CV & 18.0 & 46.6 & 11.2 & 26.8 & 53.7 & 34.8 & 22.7 & 8.8 \\
\hline F1 & $46.79^{\mathrm{ab}}$ & $3.0^{\mathrm{b}}$ & $1.19^{\mathrm{b}}$ & $81.95^{\mathrm{b}}$ & $394.0^{\mathrm{a}}$ & $34.1^{\mathrm{a}}$ & $198.0^{\mathrm{a}}$ & $42.4^{\mathrm{b}}$ \\
\hline F2 & $54.21^{\mathrm{a}}$ & $6.8^{\mathrm{a}}$ & $1.06^{\mathrm{b}}$ & $79.51^{\mathrm{b}}$ & $339.0^{\mathrm{ab}}$ & $26.4^{\mathrm{a}}$ & $163.0^{\mathrm{a}}$ & $43.6^{\mathrm{b}}$ \\
\hline F3 & $42.08^{\mathrm{b}}$ & $1.4^{\mathrm{bc}}$ & $1.24^{\mathrm{ab}}$ & $69.76^{\mathrm{b}}$ & $166.0^{\mathrm{c}}$ & $20.0^{\mathrm{a}}$ & $184.0^{\mathrm{a}}$ & $45.2^{\mathrm{b}}$ \\
\hline F4 & $32.10^{\mathrm{c}}$ & $1.2^{\mathrm{c}}$ & $1.42^{\mathrm{a}}$ & $84.88^{\mathrm{b}}$ & $140.0^{\mathrm{c}}$ & $23.2^{\mathrm{a}}$ & $152.0^{\mathrm{a}}$ & $48.2^{\mathrm{ab}}$ \\
\hline F5 & $30.98^{\mathrm{c}}$ & $5.6^{\mathrm{a}}$ & $1.44^{\mathrm{a}}$ & $80.00^{\mathrm{b}}$ & $80.8^{\mathrm{c}}$ & $21.2^{\mathrm{a}}$ & $174.0^{\mathrm{a}}$ & $52.8^{\mathrm{a}}$ \\
\hline F6 & $43.09^{\mathrm{b}}$ & $1.8^{\mathrm{bc}}$ & $1.22^{\mathrm{b}}$ & $132.68^{\mathrm{a}}$ & $200.0^{\mathrm{bc}}$ & $30.6^{\mathrm{a}}$ & $183.0^{\mathrm{a}}$ & $45.1^{\mathrm{b}}$ \\
\hline
\end{tabular}

\section{Performance Indicators}

Field capacity (FC) varied from 0.0255 to $0.0407 \mathrm{ha} / \mathrm{h}(\bar{x}=0.0308 \mathrm{ha} / \mathrm{h}, \mathrm{s}=0.0056)$ and showed significantly higher positive relationship $\left(\mathrm{P}=0.001, \mathrm{R}^{2}=98.99 \%\right)$ with cone index $\left(\beta_{1}=0.0002, \mathrm{P}=0.001\right)$ and height of plant $\left(\beta_{1}=0.0006, \mathrm{P}=0.006\right)$ at $\mathrm{p}<0.05$. Further, this cultivator worked up to $33 \mathrm{~mm}$ depth. Supportive results was reported by many other researches also. Comparative performance evaluations conducted recently by Alizadeh, (2011) and Senavirathne et al., (2016) revealed that FC of power weeder is around 0.085 and $0.04 \mathrm{ha} / \mathrm{h}$, respectively. Further, Tajuddin (2009) in India and Wijekoonet al., (2008) in Sri Lanka developed power weeders and reported that FC of them were around 0.075 and 0.064 $\mathrm{ha} / \mathrm{h}$, respectively which are fairly higher with the presently measured FC. As reported Kumar, et al., in 2014, the field capacity of tool/implement is due to the width of soil cutting part and forward speed. In this cultivator, the working width $90 \mathrm{~cm}$ is fixed and average travelling speed $7.6 \mathrm{~m} / \mathrm{min}$ is very low. Hence FC could be further increased by using higher forward speeds through higher gear ratios. However, it would badly affect to the weeding efficiency and plant damage percentage too. 
Field efficiency varied from 71.41 to $96.06 \%(\bar{x}=83.25 \%, \mathrm{~s}=9.89)$ showing significantly higher relationship $\left(\mathrm{P}=0.007, \mathrm{R}^{2}=96.32 \%\right)$ with standing water $\left(\beta_{1}=2.177, \mathrm{P}=0.021\right)$ and plant population $\left(\beta_{1}=-0.4599, \mathrm{P}=0.007\right)$ at $\mathrm{p}<0.05$. Similar results were discussed in several studies carried-out recently. Alizadeh (2011) and Senavirathne, et al., (2016) measured FC of power weeder as $83.5 \%$ and $88.3 \%$, respectively, in performance comparison evaluations.

Weeding efficiency varied from 69.1 to $89.3 \%(\bar{x}=80.0 \%, \mathrm{~s}=8.7)$ showing a significantly higher negative relationship $\left(\mathrm{P}=0.006, \mathrm{R}^{2}=87.21 \%\right)$ with soil bulk density $\left(\beta_{1}=-56.4\right.$, $\mathrm{P}=0.006)$ at $\mathrm{p}<0.05$. Further, it gave partial weeding efficiencies for major weed categories such as; $76 \%$ for sedges, $78 \%$ for grasses and $76 \%$ for broad leaves. Recently conducted comparison performance evaluations by Alizadeh, (2011) and Senevirathne et al., (2016) reported that, weeding efficiency for power weeder and manual weeding were around 83.5 and $62.29 \%$, respectively which matches with present results. Wijekoon et al., (2008) developed a power weeder and reported its weeding efficiency as $92.86 \%$ which is slightly higher value, since manual weeding was practiced in intra row space.

Plant damaged percentage (PD) varied from 1.54 to $13.33 \%(\bar{x}=6.34 \%, \mathrm{~s}=4.91)$ and did not show any significant relationship with the test field conditions at $\mathrm{p}<0.05$. Results of a comparison performance evaluation conducted by Alizadeh (2011) and Senevirathne et al., (2016) revealed that the PD of power weeders are around $3.86 \%$ and $0.77 \%$, respectively. Beside, Wijekoon et al., (2008) reported zero PD in testing of lowland power weeder, which are lower than presently observed PD. This is mainly due to the absence of the guard for weeding unit, which could have prevented injury to the plant. As Srinivas, et al., (2010) stated, greater depth of cut also caused the uprooting of rice plants.

Performance index (PI) of a weeding implement would be directly related to the field capacity, weeding efficiency and inversely related to power exerted (Srinivas et al., 2010). Hence, it would be a good criteria to assess the overall machine performance of mechanical w eeders PI varied from 427.1 to $814.2(\bar{x}=580, \mathrm{~s}=152.2)$ showing significantly higher negative relationship $\left(\mathrm{P}=0.033, \mathrm{R}^{2}=72.03\right)$ with height of the weed $\left(\beta_{1}=-23.3, \mathrm{P}=0.033\right)$ at $\mathrm{p}<0.05$. Moreover, it consumes $0.319 \mathrm{~kW}$. Wijekoonet al., 2008 developed a lowland power weeder and reported its PI as 156.3. Besides, Senavirathne et al., (2016) reported PI as 416.65 in comparison evaluation, which are comparatively lower than presently observed one.

Maximum tiller number (Tn) varied from 17 to $26(\bar{x}=22$, s=3.18) showing significantly higher negative relationship $\left(\mathrm{P}=0.008, \mathrm{R}^{2}=96.1 \%\right)$ with standing water $\left(\beta_{1}=-1.016\right.$, $\mathrm{P}=0.008)$ and weed density $\left(\beta_{1}=-0.01238, \mathrm{P}=0.028\right)$ at $\mathrm{p}<0.05$. As reported by Senevirathne, et al., (2016) Tn of power weeder is to be around 12.25 which is lower than the presently observed value.

Paddy yield varied from 4,266 to $8,689 \mathrm{~kg} / \mathrm{ha}(\bar{x}=6,968 \mathrm{~kg} / \mathrm{ha}$, s=1,992). Further, there was no any significant relationship with the field conditions at $\mathrm{p}<0.05$. As per Seneverathne $e t$ al., (2016), this is slightly higher yield gain than that in comparative performance evaluation (2583 kg/ha).

Cost of weeding $(\mathrm{Cw})$ varied from Rs. 6,014 to Rs.8,739 per ha ( $\bar{x}=\mathrm{Rs.7,671.00}$ per ha, $\mathrm{s}=1,050)$ showing significantly higher negative relationship $\left(\mathrm{P}=0.005, \mathrm{R}^{2}=96.99 \%\right)$ with cone index $\left(\beta_{1}=-40.9, \mathrm{P}=0.003\right)$ and height of plant $\left(\beta_{1}=-155.5, \mathrm{P}=0.012\right)$ at $\mathrm{p}<0.05$. Further, 
labour requirement and the fuel consumption of power cultivator were $33 \mathrm{man}-\mathrm{h} / \mathrm{ha}$ and $0.503 \mathrm{~L} / \mathrm{h}$, respectively. As reported by Seneverathne et al. (2016), their weeding cost was only Rs. 6583.00 per ha. In general, the cost of operation of power weeders could be more due to higher purchasing price (Rs. $72,500.00$ for this cultivator) which is responsible for increasing fixed cost of these implements in spite of higher FC.

\section{CONCLUSIONS}

In the practical field test the newly designed burial type lowland power cultivator attained higher satisfactory field performances; 0.03 ha/h effective field capacity, $83.25 \%$ field efficiency, $80 \%$ weeding efficiency, $6.34 \%$ plants damaged, 580 performance Index, 22 maximum number of tillers, $6968 \mathrm{~kg} /$ ha paddy yield, Rs. 7671/ha cost of weeding. Further, fuel consumption, labour and power requirement were $0.503 \mathrm{~L} / \mathrm{h}, 33 \mathrm{man}-\mathrm{h} / \mathrm{ha}$ and 0.319 $\mathrm{kW}$, respectively. Besides, tests did not report any ergonomics defect or machine breakdown throughout the test and it was easy to operate. Thus, it can be concluded that newly designed burial type lowland power cultivator could be recommended as the appropriate solution for the weeding problem of medium and large scale paddy farmers in Sri Lanka. Further, it is suggested to conduct detail ergonomic evaluation in future investigations.

Acknowledgement: The authors thank the Rajarata University of Sri Lanka (RUSL) and University of Peradeniya for providing the opportunity to make this research project a success and Mr. M.K.A.L. Jayawardena for the assistance in research activities. This research work was funded by University Grants Commission (UGC), Sri Lanka.

\section{REFERENCE}

Alizadeh, M.R. (2011). Field performance evaluation of mechanical weeders in the paddy field. Scientific Research and Essays, 6 (25): pp. 5427-5434, 30 October, 2011. DOI: 10.5897/SRE11.1412

Hunt, D. (1995). Farm power and machinery management $\left(9^{\text {th }}\right.$ Ed.). State University Press. Ames, IA.USA, Iowa.

Kepner, R.A., Bainer, R.; and Barger, E.L. (1982). Principles of Farm Machinery. $3^{\text {rd }}$ Edition. avi, West port, Connecticut.

Kumar, T.N., Kumar, A.S.; Nayak, M.; and Ramya, V. (2014). Performance evaluation of weeders. International Journal of Science, Environment and Technology, Vol. 3, No. 6, $2014,2160-2165$.

Majumdar, S.P., and Singh, R.A. (2002). Analysis of soil physical properties. Agro bios (India), Jodhpur.

RNAM. (1983). Economic and Soil Commission for Asia and Pacific Regional Network for Agricultural Machinery. RNAM Test Codes and Procedures for Farm Machinery, Technical Series No. 12.United Nations Industrial Development Organization, Bangkok, Thailand. 
Senevirathne, N.N., Weerasooriya, G.V.T.V. and Dissanayaka, D.M.D. (2016). Evaluation of comparative performances of newly designed lowland power weeder. In Undergraduate Research Symposium 2013 Proceeding. p 86.Faculty of Agriculture, Rajarata University of Sri Lanka. Anuradhapura, Sri Lanka.

Singh, R.A. (1980). Soil physical analysis. Kalyani publishers, New Delhi.

Srinivas, I., Adake, R.V., Reddy, B.S., Korwar, G.R., Thyagaraj, C.R., Dange, A., Veeraprasad, G. and Raddy, C.R. (2010). Comparative performance of different power weeders in rain fed sweet sorghum crop. Indian J. Dry land Agric. Res. \& Dev.2010 25(2), 63-67.

Tajuddin, A. (2009). Development of a power weeder for low land rice. IE (I), 90, 15 - 17.

Wijekoon, R.D.R., Bandara, M.H.M.A., and Weerasooriya, G.V.T.V. (2008). Design and development of low land power weeder. In Abstracts of Final Year Research - 2008 (Vol. 03).p 45.Faculty of Agriculture, Rajarata University of Sri Lanka, Anuradhapura, Sri Lanka.

Yadav, R. and Pund, S. (2007). Development and ergonomic evaluation of manual weeder. Agricultural Engineering International: the CIGR e-journal. Manuscript, PM 07 022. Vol. IX. October. 